\title{
Experimental study on the repair of ureteral functional regeneration with highly bioactive extracellular matrix stent
}

\author{
${ }^{*}$ Lifeng $\mathrm{Gu}^{\mathrm{A}}$, ${ }^{*}$ Xiaosong Fan ${ }^{\mathrm{A}}$, Jiancheng $\mathrm{Lu}^{\mathrm{B}}$, Bojun $\mathrm{Li}^{\mathrm{B}}$, Weijie Xia ${ }^{\mathrm{C}}$, Feiping He ${ }^{\mathrm{D}, \mathrm{E}}$, Jie Chen ${ }^{\mathrm{D}, \mathrm{E}}$, Weixing Yu${ }^{\mathrm{F}}$ \\ Department of Urology, Shaoxing Shangyu People's Hospital, China \\ A - research concept and design; $B$ - collection and/or assembly of data; $C$ - data analysis and interpretation; \\ $D$ - writing the article; $E$ - critical revision of the article; $F$ - final approval of the article
}

\author{
Address for correspondence \\ Weixing Yu \\ E-mail:yuweixingsy1y@163.com \\ Funding sources \\ None declared \\ Conflict of interest \\ None declared \\ *Lifeng Gu and Xiaosong Fan contributed equally \\ to this work.
}

Received on March 11, 2020

Reviewed on March 15, 2020

Accepted on June 2, 2020

Published online on November 16, 2020

Cite as

Gu L, Fan X, Lu J. Experimental study on the repair of ureteral functional regeneration with highly bioactive extracellular matrix stent. Adv Clin Exp Med. 2020;29(11):1367-1373. doi:10.17219/acem/123353

D0I

10.17219/acem/123353

\section{Copyright}

Copyright by Author(s)

This is an article distributed under the terms of the

Creative Commons Attribution 3.0 Unported (CC BY 3.0)

(https://creativecommons.org/licenses/by/3.0/)

\begin{abstract}
Background. The research of extracellular matrix stent (ECM) has made some progress in the repair of urethra and bladder defects.

Objectives. To observe the effects of highly bioactive ECM scaffold on the regeneration and repair of defects in long-segment ureteral replacement.

Material and methods. An animal model of long-segment ureteral defect was established and four-layer tubular highly bioactive ECM materials were prepared. After the ureteral defect was repaired through surgery, the rabbits in the negative control group were administered a non-bioactive stent, and rabbits in the observation group were treated with an ECM stent.

Results. Comparison of macro-indicators: The negative control group had a higher infection rate, a lower survival rate and more complications than the observation group $(p<0.05)$. The frequency of ureteral peristalsis in the negative control group was lower than in the observation group. In addition, the rate of urinary dysfunction was higher, and the ratio of ureteral diameter was lower in the negative control group than in the observation group (all $p<0.05)$. Comparison of histopathology: Three months after the operation, the vascular, smooth muscle and mucous membrane of the ureter in the observation group regenerated to close to normal ureteral tissue. There was no significant difference between the ureter regeneration in the repair area and the normal ureter tissue in the observation group 3 months after the operation. The number of regenerated muscle fibers in the observation group was significantly higher than that of the negative control group. Compared with the negative control group, the fibrous capsule was thicker, the percentages of CD31, CD3, CD68, CD80+, and CD163 + were higher, the scope of new smooth muscle fiber was expanded, fusion with the host muscle fibers was higher, and the neuromuscular junction (NMJ) structure was stronger in the observation group (all $p<0.05)$.
\end{abstract}

Conclusions. A highly bioactive ECM stent can better regenerate the local anatomical structure and physiological function.

Key words: extracellular matrix, ureteral defect, high biological activity, regeneration and repair 


\section{Introduction}

There are many factors that can lead to the defect of ureteral function and anatomical structure. At present, for ureteral defects larger than $2 \mathrm{~cm}$, the colon or bladder muscle flap is mainly used as a substitute, or even directly treated with the kidney transplantation. ${ }^{1}$ However, these treatment methods are always accompanied by many complications, so it is urgent to find other repair techniques. The main purpose of tissue engineering research is to repair and reconstruct damaged or non-functional organs. At present, great progress has been made in the reconstruction of urethras and bladders with tissue engineering scaffold materials. ${ }^{2,3}$ With the development and maturity of bioengineering technology, the extracellular matrix (ECM) has become important in the repair of urethra and bladder defects. ${ }^{4}$ The higher physiological requirements of the ureter than those of the bladder or urethra, a regenerated ureter should be free of urine leakage, stone formation, anastomotic stenosis, and inelasticity, and should be consistent with the host's ureteral peristalsis rhythm has largely limited the research of ECM material in ureter regeneration.

Although some studies have proposed that the ECM plays an important role in the repair of ureteral defects, research on how to make full use of its functions to promote injury repair and clinical transformation is still lacking. Our group has developed a highly bioactive ECM stent which is able to retain at least $60 \%$ of the bioactive components in the natural ECM, thus improving the anti-infectivity and reducing the loss of elasticity in the repair area. ${ }^{5}$ The ECM stent contains a variety of bioactive factors and more than $90 \%$ type I and type III collagen. After transplantation, it can be effectively degraded to produce a large number of active peptides, which increases its antibacterial ability. Therefore, the present study further applies it to animal models, discusses the changes in histopathology microscopically and the changes of ureteral dynamic function macroscopically, and explores the influence of highly bioactive ECM materials on ureteral regeneration, striving for a breakthrough in the field of ureteral regeneration.

\section{Material and methods}

\section{Experimental animal subjects}

A total of 48 male adult New Zealand rabbits, weighing $2.0-3.0 \mathrm{~kg}$ (average: $2.68 \mathrm{~kg}$ ), were provided by the experimental animal center of Zhejiang University, Shaoxing, China. During the experiment, the animals were treated according to the requirements of animal ethics.

\section{Establishment of long-segment ureteral defect animal model}

The rabbits were anesthetized using general pentobarbital sodium $(30 \mathrm{mg} / \mathrm{kg}$ ) through the ear vein. The related operation area was sterilized and paved with a sterile sheet. Through the posterior peritoneum channel, a blunt separation was carried out in the muscular space along a left straight incision of the spine. The upper and middle ureters were found and separated along the psoas major muscle, and sections of ureters with a length of $1.0 \mathrm{~cm}$ were excised.

\section{Preparation of the highly bioactive ECM tubular stent}

Fresh pig jejunum (warm ischemia time $<10 \mathrm{~min}$ ) was rinsed in phosphate-buffered saline (PBS) and added to a Hanks solution at $4{ }^{\circ} \mathrm{C}$. The serous layer, mucosal layer and muscular layer of jejunum were removed using mechanical force, and the residual cell components were washed using double-distilled water to obtain the porcine small intestinal submucosa (P-SIS). Then, the P-SIS was stirred in $0.5 \%$ pancreatin $+0.5 \%$ EDTA for $10 \mathrm{~h}$, washed with PBS and double-distilled water to remove the pancreatin, immersed in phenol chloroform and methanol (volume ratio: 1:3), and immersed in the fume hood for $12 \mathrm{~h}$ (the liquid was changed every $3 \mathrm{~h}$ ). Finally, PBS and double-distilled water were used to clean the residual reagent.

The P-SIS was immersed in 2.5\% SDS for $16 \mathrm{~h}$, then rinsed with PBS and double-distilled water to remove the SDS. After that, the P-SIS was added to $10 \%$ ethanol containing $0.8 \%$ peracetic acid (PAA), and it was rinsed with PBS and double-distilled water to remove the PAA.

An FR 3.0 double-J tube (Huasheng Medical Materials Co., Ltd., Jiangsu, China) was used as an inner support, and P-SIS was made into a tubular material with a specific diameter, which was overlapped with 4 layers using the vacuum lamination method. It was then dried completely at $-120^{\circ} \mathrm{C}$ in a freeze-drying machine, and sterilized with ethylene oxide in sterilized paper plastic bags. ${ }^{6}$

\section{Experimental grouping}

A total of 48 rabbits were randomly divided into a negative control group and an observation group (24 rabbits in each group). In the negative control group, the $2.0-\mathrm{mm}$ diameter silica gel double-J tube was used as a stent with one end placed in the renal pelvis and the other end placed inside the bladder. Transplantation was conducted with the same length of a non-bioactive stent. The upper and lower ends of the ureter were anastomosed with the nonbioactive stent using 9-0 absorbable sutures under microscope. In the observation group, the $2.0 \mathrm{~mm}$ diameter 

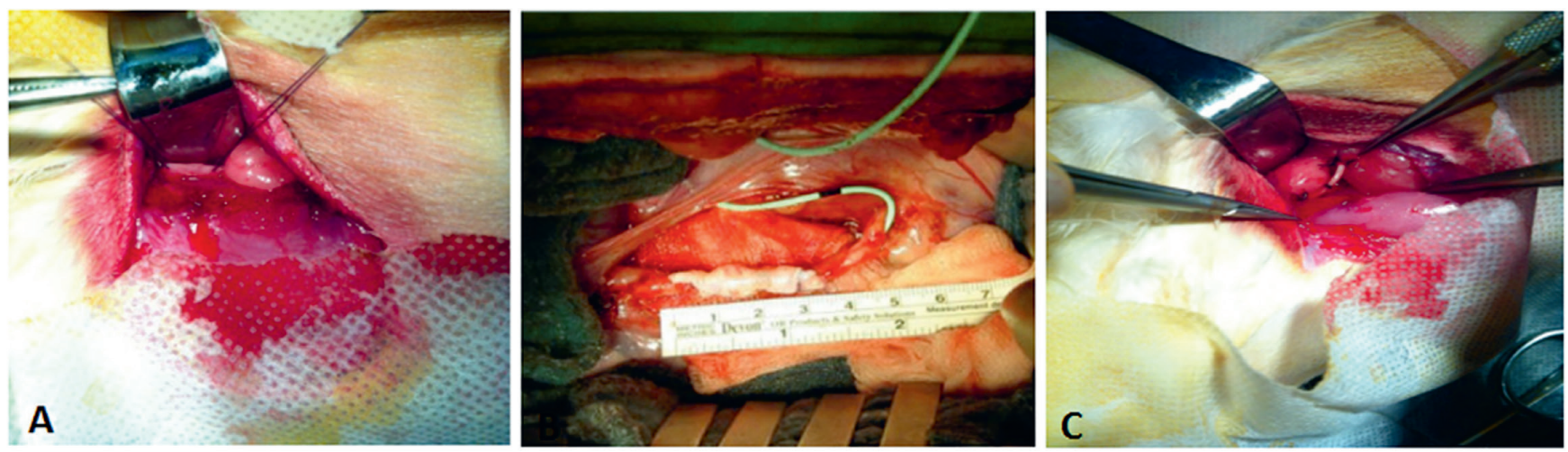

Fig. 1. Process of the operation: (A) establishment of the ureteral injury animal model; (B) implantation of the inactive stent; (C) implantation of the highly bioactive stent

silica gel double-J tube was used as a stent with one end placed in the renal pelvis and the other end placed inside the bladder. Transplantation was conducted with the same length of tubular highly bioactive ECM stent. The upper and lower ends of the ureter were anastomosed with the ECM stent using 5-0 absorbable sutures under microscope. Four or 5 stitches were sutured at each end, and the subcutaneous tissue and skin were sutured intermittently with 3-0 silk thread. An intramuscular injection of 1.6 million units of penicillin was administered intraoperatively in order to prevent infection during the operation (Fig. 1).

\section{Observation index}

\section{Macro indicators}

The infection and survival rates were recorded at 2 weeks and $1,2,3,4$, and 6 months postoperatively. The incidence of hydronephrosis, renal function damage, ureteral stricture, and urinary leakage were studied using pyelography after removal of the double-J tube. The peristalsis and micturition functions of the ureter were also observed. The dynamic function of the ureter was evaluated by the diameter ratio of the 2 ureters at the same stage.

\section{Histopathological index}

The hematoxylin \& eosin (H\&E) staining results were checked at 2 weeks and 1, 2, 3, 4, and 6 months postoperatively, and the number and structure of ureteral regenerated muscle fibers were observed under electron microscope. Immunofluorescence staining was used to detect the cell-material response, including surrounding tissue wrapping (thickness of the fibrous capsule), the percentage of vascularization (CD31), infiltrating cells (CD3 and CD68), and monocyte macrophages $\left(\mathrm{CD} 80^{+}\right.$and $\left.\mathrm{CD} 163^{+}\right)$. The material remodeling and regeneration of intima and smooth muscle innervation were detected. Each group had 4 animal subjects at each time point.

\section{Detection methods}

Intravenous pyelography

The double-J tube was removed and intravenous pyelography was conducted. After the anesthesia took effect, the rabbits were fixed on the X-ray examination table to establish the venous access. An injection of $20 \mathrm{~mL}$ of $60 \%$ meglumine diatrizoate was made intravenously and an abdominal flat film was taken $5 \mathrm{~min}, 10 \mathrm{~min}$ and $20 \mathrm{~min}$ later. The incidence of hydronephrosis, renal function damage (serum creatinine level at least 2 times higher than the baseline value), ureteral stenosis, and urinary leakage was examined. The peristalsis and micturition functions of the ureter were observed, and the dynamic function of the ureter was evaluated by the ratio of the diameter of the 2 ureters at the same stage.

\section{Examination of ureteral dynamic function}

The whole ureter of both sides was excised, the distal side was ligated and the proximal one was connected with the infusion tube perfusion system. The ureter was perfused with $60 \mathrm{~cm} \mathrm{H}_{2} \mathrm{O}$ pressure, and the ratio of the diameters of the 2 ureters at the same stage was used as the observation index. The results were automatically read out using the own software of the system (Urodynamic Analyzer; MMS, Enschede, the Netherlands).

\section{Tissue section and pathological analysis}

The normal ureteral tissue and ureteral tissue repaired using ECM were made into paraffin sections. For H\&E staining, the sections were washed with distilled water, stained with hematoxylin solution for several minutes, decolorized with acid water and ammonia water, dehydrated with an alcohol gradient, stained with eosin, sealed with xylene, and observed under a microscope. For immunofluorescence staining, the sections were washed in PBS and incubated in Tris-buffered saline (TBS) containing 
$0.1 \%$ Triton $\mathrm{X}-100+0.1 \%$ calf serum protein for $20 \mathrm{~min}$. The antigen repair buffer $(100 \mathrm{mM}$ of Tris and 5\% urea; $\mathrm{pH}$ : 9.5) was added and heated at $95^{\circ} \mathrm{C}$ for $10 \mathrm{~min}$, then washed with PBS. The cells were incubated with PBS with Tween ${ }^{\circledR} 20$ (PBST) containing 1\% bovine serum albumin (BSA) and $22.52 \mathrm{mg} / \mathrm{mL}$ of glycine for $30 \mathrm{~min}$ to block the antibody; then, they were washed with PBS. After being incubated with monoclonal antibody against CD31, CD3, $\mathrm{CD} 68, \mathrm{CD}^{+} 0^{+}, \mathrm{CD} 163^{+}$, and muscle fiber (Sigma-Aldrich, St. Louis, USA), the cells were washed with PBS and incubated with corresponding fluorescence labeled secondary antibodies (Sigma-Aldrich). Four slices were studied in each animal and 4 animals were randomly selected from each group. Four visual fields were taken from each slice and observed under laser confocal microscope. The results were calculated as average values.

\section{Statistical analysis}

The IBM SPSS v. 20.0 statistical software (IBM Corp., Armonk, USA) was used for the statistical analysis. The measurement data is expressed as means \pm standard deviation (SD). The t-test of independent samples was used for intergroup comparisons. The numerical data is expressed using number of cases (percentage), and a $\chi^{2}$ test was used for comparison between groups. P-values $<0.05$ indicated statistically significant differences.

\section{Results}

\section{Comparison of infection and survival rate between the 2 groups}

With the prolongation of the observation time, the infection rate increased and the survival rate decreased in the negative control group; there was a significant difference compared with the observation group $(\mathrm{p}<0.05)$ (Table 1).

\section{Comparison of ureteral function between the 2 groups}

The incidence of hydronephrosis, renal function damage, ureteral stricture, and urinary leakage in the negative control group increased and was significantly higher than in the observation group $(\mathrm{p}<0.05)$. The frequency of ureteral peristalsis and the ratio of ureteral diameter in the negative control group were lower than in the observation group; the incidence of urinary dysfunction was higher than in the observation group ( $\mathrm{p}<0.05$ ). (Table 2 and Fig. 2,3).

\section{Hematoxylin \& eosin staining}

The histopathological examination revealed that, compared with the negative control group, the repair area of the ureter in the observation group covered the epithelium. Additionally, with the passage of time, the ureteral blood vessels, smooth muscle and mucosa regenerated more and were arranged more regularly (Fig. 4). The thickness of the epithelium was increased and the number of blood vessels was higher at each time point than in the negative control group.

\section{Regenerated muscle fiber and cell-material reaction of the ureter}

Compared with the negative control group, the number of regenerated muscle fibers of ureters in the observation group increased noticeably as observed under electron microscope, the fibrous capsule was thicker, the percentages of CD31, CD3, CD68, CD80 ${ }^{+}$, and $\mathrm{CD} 163^{+}$were higher, the scope of synovium fiber was greater, fusion with host

Table 1. Comparison of infection and survival rate between the 2 groups

\begin{tabular}{|l|c|c|c|}
\multicolumn{1}{|c|}{ Groups } & $\begin{array}{c}\text { Negative control group } \\
(\mathbf{n = 2 4 )}\end{array}$ & $\begin{array}{c}\text { Observation group } \\
(\mathbf{n}=24)\end{array}$ & $x^{2}$ \\
\hline Six-month infection rate & $6(25.0 \%)$ & $1(4.2 \%)$ & 5.400 \\
\hline Six-month survival rate & $17(70.8 \%)$ & $22(91.7 \%)$ & 0.020 \\
\hline
\end{tabular}

Table 2. Comparison of ureteral function between the 2 groups

\begin{tabular}{|c|c|c|c|c|}
\hline Groups & Negative control group $(n=24)$ & Observation group $(n=24)$ & $t / x^{2}$ & $p$-value \\
\hline Hydronephrosis & 1 & 1 & 0.000 & 1.000 \\
\hline Renal function damage & 3 & 1 & 0.000 & 1.000 \\
\hline Ureteral stricture & 3 & 1 & 0.000 & 1.000 \\
\hline Urinary leakage & 2 & 0 & 0.000 & 1.000 \\
\hline Total incidence & $9(37.5 \%)$ & $3(12.5 \%)$ & 4.448 & 0.007 \\
\hline Ureteral peristalsis frequency [times/h] & $1.2 \pm 0.3$ & $1.6 \pm 0.4$ & 3.452 & 0.003 \\
\hline Urethral dysfunction & $7(29.2 \%)$ & $1(4.2 \%)$ & 5.365 & 0.015 \\
\hline Ureter diameter ratio & $0.6 \pm 0.3$ & $0.8 \pm 0.3$ & 3.265 & 0.006 \\
\hline
\end{tabular}



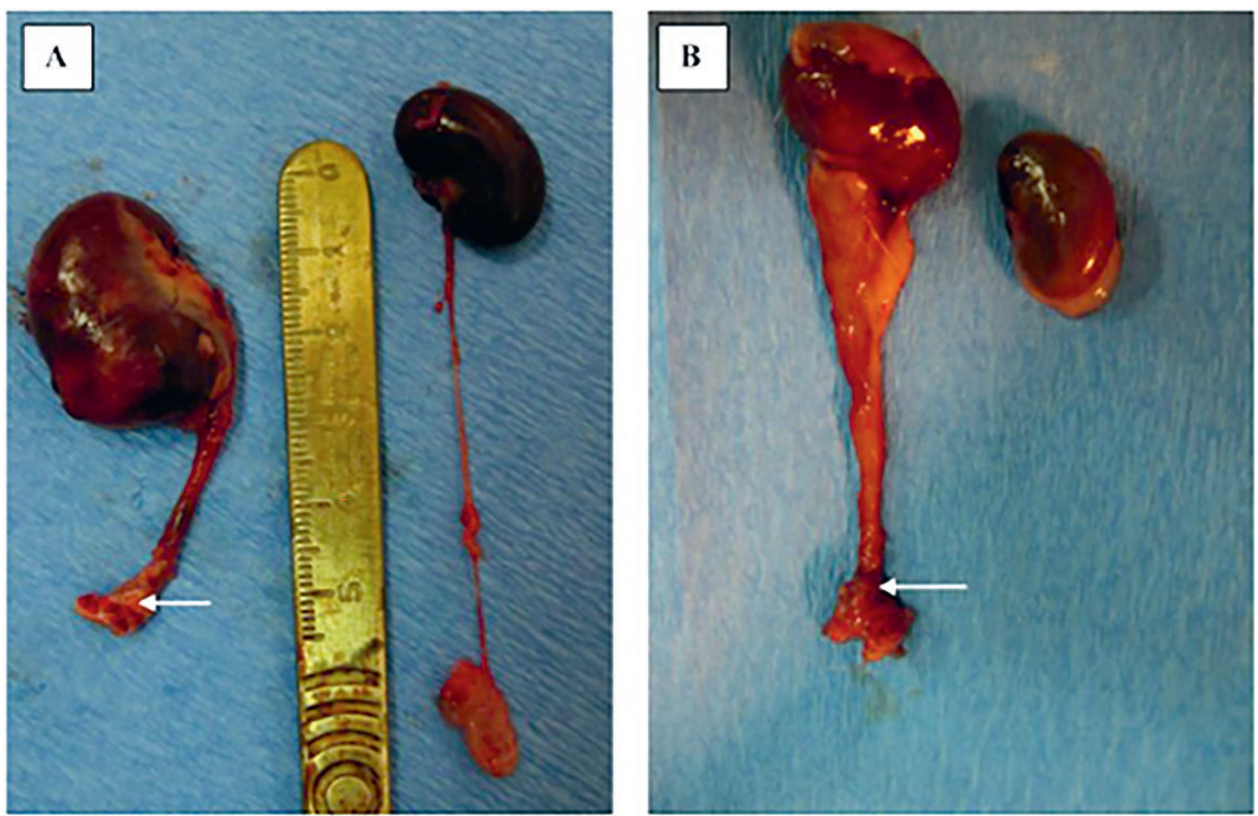

Fig. 2. Comparison of ureteral function between the 2 groups through gross observation of the kidney and ureter. (A) Negative control group: the ureter of the affected side adheres to the surrounding tissue, and the materials in the repair area are systematized. (B) Observation group: there was no difference in the appearance of the kidneys on the 2 sides; the arrow indicates the repair area



Fig. 3. General view of bilateral kidneys and ureters 3 months after operation muscle fibers was higher, and the number of neuromuscular junction (NMJ) structure increased (all p < 0.05) (Table 3 and Fig. 5).

\section{Discussion}

In this study, a rabbit model of long-segment ureteral defect was established and 4 layers of tubular highly bioactive ECM materials were prepared. The results showed that the ECM material group had a lower infection rate, a higher survival rate, a lower incidence of hydronephrosis, renal function damage, ureteral stricture and urinary leakage, a higher frequency of ureteral peristalsis, a decreased incidence of ureteral dysfunction, and improved ureteral dynamic function. These results indicate that it is feasible to repair a ureteral defect with ECM material. The mechanism of action may be related to the following aspects:

Table 3. Comparative study on the cell-material reaction of ureteral regenerated muscle fibers (per high-power field)

\begin{tabular}{|c|c|c|c|c|}
\hline Groups & Negative control group & Observation group & $\mathrm{t}$ & $p$-value \\
\hline Cases & 4 & 4 & - & - \\
\hline Number of regenerated muscle fibers & $2.6 \pm 0.9$ & $3.5 \pm 1.1$ & 3.625 & 0.02 \\
\hline Thickness of fibrous capsule $[\mu \mathrm{m}]$ & $10.8 \pm 5.4$ & $12.3 \pm 5.6$ & 3.321 & 0.024 \\
\hline CD31 [\%] & $26.7 \pm 8.4$ & $35.6 \pm 9.4$ & 15.632 & 0 \\
\hline CD3 $[\%]$ & $24.6 \pm 7.9$ & $32.4 \pm 8.6$ & 10.254 & 0 \\
\hline CD68 [\%] & $36.9 \pm 13.5$ & $41.2 \pm 12.3$ & 14.528 & 0 \\
\hline $\mathrm{CD} 80^{+}[\%]$ & $23.5 \pm 11.3$ & $29.8 \pm 10.2$ & 9.635 & 0 \\
\hline $\mathrm{CD}_{163}{ }^{+}[\%]$ & $24.5 \pm 12.2$ & $30.6 \pm 9.5$ & 8.524 & 0 \\
\hline Number of newborn smooth muscle fibers & $2.5 \pm 0.8$ & $3.2 \pm 0.9$ & 3.065 & 0.031 \\
\hline Number of neuromuscular junctions & $2.1 \pm 0.7$ & $2.6 \pm 0.8$ & 2.968 & 0.035 \\
\hline
\end{tabular}



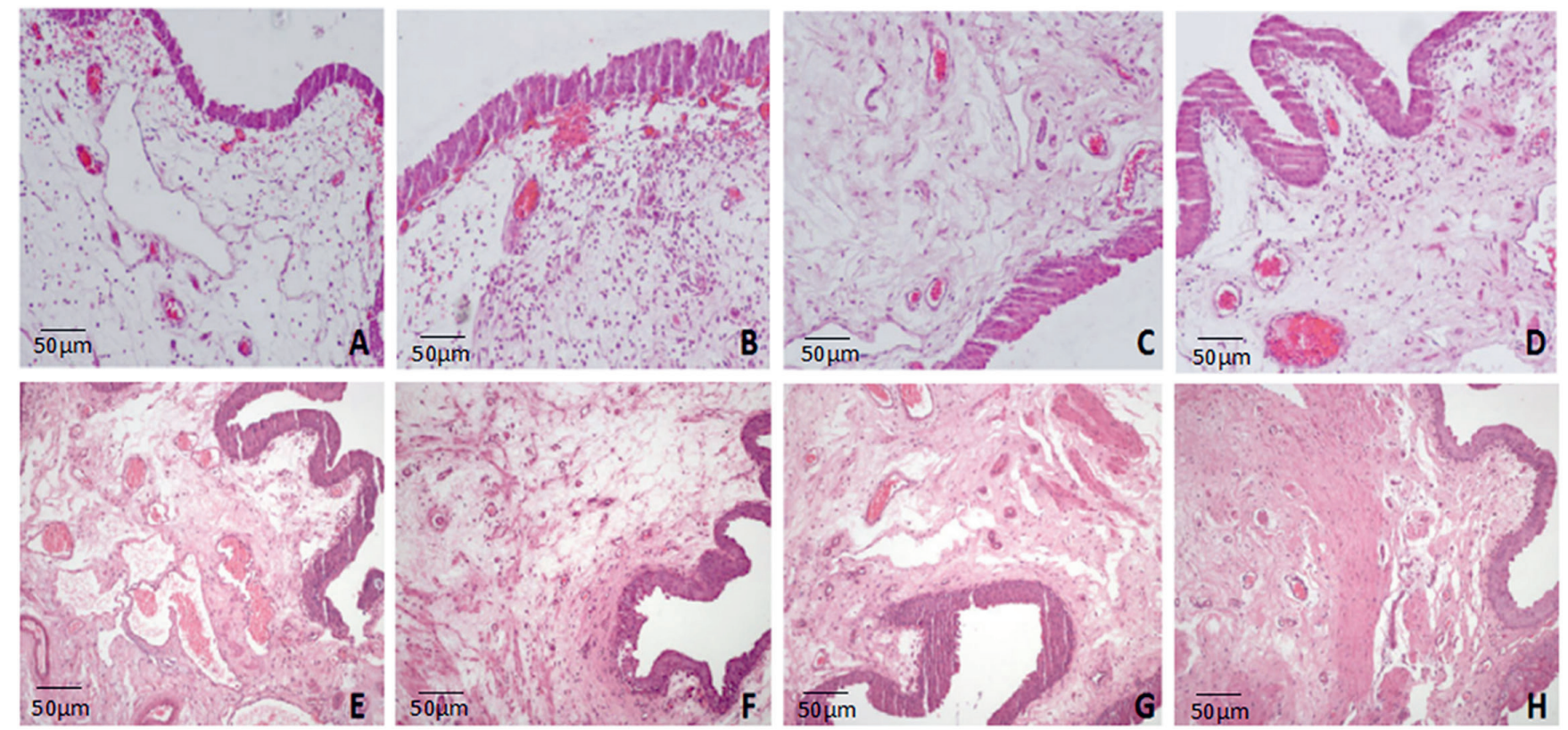

Fig. 4. H\&E staining ( $\times 100)$; (A-D) epithelial regeneration was seen in the observation group 1, 2, 3, and 6 months after operation; (E-H) epithelial regeneration was seen in the control group 1, 2, 3, and 6 months after the operation
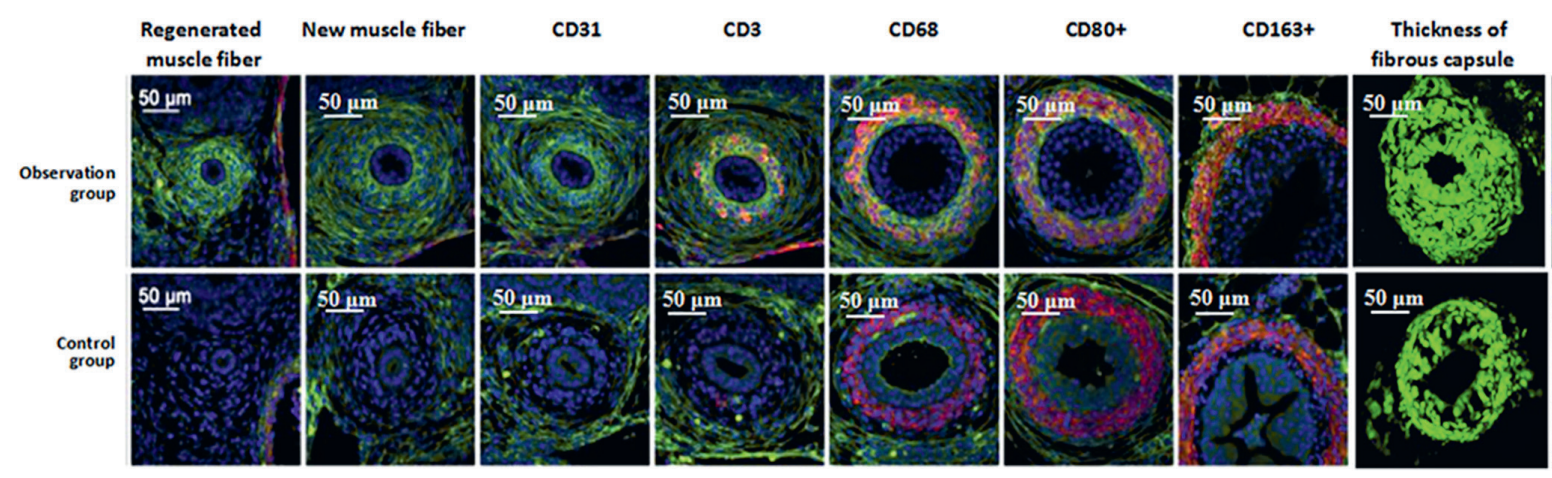

NMJ

Fig. 5. Immunofluorescence detection of cell-material reaction in each group. Muscle fibers, CD31- and NMJ-positive shown in green; CD3-, CD68-, CD80+and CD163+-positive shown in red. The fluorescence intensity of the above index in the observation group was higher than that of the negative control group

1. The ECM does not contain high-antigenicity cell components obtained through special decellularization, and only retains low antigenic substances such as collagen, proteoglycan, glycoprotein, etc., which tend not to lead to rejection after transplantation.

2. This operation retains a complete three-dimensional space for cell survival and a full range of bioactive ingredients, which are conducive to cell nutrition, gas exchange and waste discharge. ${ }^{6-12}$

3. In addition, ECM can ensure enough biomechanical strength to meet the needs of tissue repair and reconstruction, can attract and regulate the growth and differentiation of host cells in the scaffold, and can form new self-tissue to complete the specific repair and functional recovery from defects. ${ }^{13-17}$

The transplanted stent needs not only to reduce the abnormal immune rejection and tissue proliferation, but also to promote a normal connection between an ECM stent and the surrounding normal ureteral tissue cells, and to increase vascularization. ${ }^{18-20}$ The percentages of surrounding tissue wrapping, vascularization, infiltrating cells, and monocyte macrophages are commonly used to reflect the intensity of cell-material reaction between the stent and surrounding normal ureteral tissue. Our histopathological observation showed that there was no significant difference between the ureter regeneration in the repair area and the normal ureter tissue in the observation group after 3 months of treatment. Under the electron microscope, we found that the number of regenerated muscle fibers in the ureters had increased significantly, the thickness of the fibrous capsules had increased, the percentage of CD31, CD3, CD68, CD80 ${ }^{+}$, and $\mathrm{CD} 163^{+}$had increased, the scope of new smooth muscle fibers had expanded, and the NMJ structure had increased $(p<0.05)$. Then, the stent was replaced by ureteral tissue 6 months after operation. Histological observation showed the growth 
of a transitional epithelium and ureteral myometrium, a large number of blood vessels, and no inflammatory cells. These results are generally consistent with those of other studies. ${ }^{21}$ They also show that the highly bioactive ECM scaffolds prepared by us are compatible with the surrounding tissues.

\section{Conclusions}

In conclusion, a highly bioactive ECM stent can be used to repair a ureteral defect effectively by regenerating local anatomical structure and physiological function, as an ideal material for ureteral reconstruction. However, we have not verified whether the highly bioactive ECM scaffold decomposes after replantation in vivo, and whether it also has certain promoting activity in local cells in vivo.

\section{ORCID iDs}

Lifeng Gu (1) https://orcid.org/0000-0002-0980-4393

Xiaosong Fan (1) https://orcid.org/0000-0002-4122-5906

Jiancheng Lu (1) https://orcid.org/0000-0002-0093-5370

Bojun Li (i) https://orcid.org/0000-0001-7471-7897

Weijie Xia (1) https://orcid.org/0000-0002-6490-7483

Feiping He (1) https://orcid.org/0000-0002-3411-9195

Jie Chen (10) https://orcid.org/0000-0001-9388-2695

Weixing Yu (1) https://orcid.org/0000-0002-9739-6659

\section{References}

1. Siddighi S, Yune JJ, Kwon NB, Hardesty JS, Kim JH, Chan PJ. Perioperative serum creatinine changes and ureteral injury. Int Urol Nephrol. 2017:49(11):1915-1919.

2. Choi YS, Lee SH, Cho HJ, Lee DH, Kim KS. Outcomes of ureteroscopic double-J ureteral stenting for distal ureteral injury after gynecologic surgery. Int Urogynecol J. 2018;29(9):1397-1402.

3. Ordorica R, Wiegand LR, Webster JC, Lockhart JL. Ureteral replacement and onlay repair with reconfigured intestinal segments.J Urol. 2014;191(5):1301-1306.

4. Tokhmafshan F, Brophy PD, Gbadegesin RA, Gupta IR. Vesicoureteral reflux and the extracellular matrix connection. Pediatr Nephrol. 2017; 32(4):565-576.

5. Zhao Z, Liu D, Chen Y, et al. Ureter tissue engineering with vessel extracellular matrix and differentiated urine-derived stem cells. Acta Biomater. 2019;88:266-279.

6. Yi S, Ding F, Gong L, Gu X. Extracellular matrix scaffolds for tissue engineering and regenerative medicine. Curr Stem Cell Res Ther. 2017; 12(3):233-246.
7. Lazica DA, Ubrig B, Brandt AS, von Rundstedt FC, Roth S. Ureteral substitution with reconfigured colon: Long-term follow-up. J Urol. 2012;187(2):542-548.

8. Kloskowski T, Kowalczyk T, Nowacki M, Drewa T. Tissue engineering and ureter regeneration: Is it possible? Int J Artif Organs. 2013;36(6): 392-405.

9. Simaioforidis V, de Jonge P, Sloff M, Oosterwijk E, Geutjes P, Feitz WFJ. Ureteral tissue engineering: Where are we and how to proceed? Tissue Eng Part B Rev. 2013;19(5):413-419.

10. Sapora JA, Hardie RJ, Evans N. Use of a subcutaneous ureteral bypass device for treatment of bilateral proximal ureteral injury in a 9-monthold cat. JFMS Open Rep. 2019;5(1):2055116919831856.

11. Zhang J, Hu Z, Billiar TR, Badylak SF. Preparation of volumetric skeletal muscle whole organ acellular matrix to regenerate contractile, vascularized, innervated muscle in rodent and canine model. $J \mathrm{Am}$ Coll Surg. 2013;217(3):S145.

12. Song JJ, Guyette JP, Gilpin SE, Gonzalez G, Vacanti JP, Ott HC. Regeneration and experimental orthotopic transplantation of a bioengineered kidney. Nat Med. 2013;19(5):646-651.

13. Versteegden LR, van Kampen KA, Janke HP, et al. Tubular collagen scaffolds with radial elasticity for hollow organ regeneration. Acta Biomater. 2017;52:1-8.

14. Xiao S-W, Wang P-C, Fu W-J, Wang Z-X, Li G, Zhang X. Novel perfusion-decellularized method to prepare decellularized ureters for ureteral tissue-engineered repair. J Biosci Bioeng. 2016;122(6):758-764.

15. Murala JSK, Sassalos P, Owens ST, Ohye RG. Porcine small intestine submucosa cylinder valve for mitral and tricuspid valve replacement. J Thorac Cardiovasc Surg. 2017;154(3):e57-e59.

16. Guest JF, Weidlich $D$, Singh $H$, et al. Cost-effectiveness of using adjunctive porcine small intestine submucosa tri-layer matrix compared with standard care in managing diabetic foot ulcers in the US. J Wound Care. 2017;26(Suppl 1):S12-S24.

17. Zhang $X$, Fang $Z$, Cho $E$, et al. Use of a novel, reinforced, low immunogenic, porcine small intestine submucosa patch to repair a supraspinatus tendon defect in a rabbit model. Biomed Res Int. 2019;2019: 9346567-9346567.

18. Chai Y, Xu J, Zhang Y, Zhang J, Hu Z, Zhou H. Evaluation of decellularization protocols for production of porcine small intestine submucosa for use in abdominal wall reconstruction. Hernia. 2019. doi:10.1007/ s10029-019-01954-4.

19. Sous Naasani LI, Rodrigues C, Azevedo JG, Damo Souza AF, Buchner S, Wink MR. Comparison of human denuded amniotic membrane and porcine small intestine submucosa as scaffolds for limbal mesenchymal stem cells. Stem Cell Rev Rep. 2018;14(5):744-754.

20. Nherera LM, Romanelli M, Trueman P, Dini V. An overview of clinical and health economic evidence regarding porcine small intestine submucosa extracellular matrix in the management of chronic wounds and burns. Ostomy Wound Manage. 2017;63(12):38-47.

21. Bryant $D$, Holtby $R$, Willits $K$, et al. A randomized clinical trial to compare the effectiveness of rotator cuff repair with or without augmentation using porcine small intestine submucosa for patients with moderate to large rotator cuff tears: A pilot study. J Shoulder Elbow Surg. 2016;25(10):1623-1633. 